\title{
Evaluation of EUV resist performance using interference lithography
}

\author{
E. Buitrago ${ }^{1}$, O. Yildirim ${ }^{2}$, C. Verspaget ${ }^{2}$, N. Tsugama ${ }^{2}$, R. Hoefnagels ${ }^{2}$, G. Rispens ${ }^{2}$ and Y. Ekinci ${ }^{1}$ \\ ${ }^{1}$ Laboratory for Micro- and Nanotechnology, Paul Scherrer Institute, CH-5232 Villigen PSI, \\ Switzerland, ${ }^{2}$ ASML Netherlands B.V., De Run 6501, 5504 DR Veldhoven, The Netherlands
}

\author{
Keywords: EUV Lithography, Interference Lithography, CAR, photoresist, 13 nm HP
}

\begin{abstract}
Extreme ultraviolet lithography (EUVL) stands as the most promising solution for the fabrication of future technology nodes in the semiconductor industry. Nonetheless, the successful introduction of EUVL into the extremely competitive and stringent high-volume manufacturing (HVM) phase remains uncertain partly because of the still limiting performance of EUV resists below $16 \mathrm{~nm}$ half-pitch (HP) resolution. Particularly, there exists a trade-off relationship between resolution (half-pitch), sensitivity (dose) and line-edge roughness (LER) that can be achieved with existing materials. This trade-off ultimately hampers their performance and extendibility towards future technology nodes. Here we present a comparative study of highly promising chemically amplified resists (CARs) that have been evaluated using the EUV interference lithography (EUV-IL) tool at the Swiss Light Source (SLS) synchrotron facility in the Paul Scherrer Institute (PSI). In this study we have focused on the performance qualification of different resists mainly for $18 \mathrm{~nm}$ and $16 \mathrm{~nm}$ half-pitch line/space resolution $(\mathrm{L} / \mathrm{S}=1: 1)$. Among the most promising candidates tested, there are a few choices that allow for $16 \mathrm{~nm}$ HP resolution to be achieved with high exposure latitude (up to $\sim 33 \%$ ), low LER (down to $3.3 \mathrm{~nm}$ or $\sim 20 \%$ of critical dimension $\mathrm{CD}$ ) and low dose-to-size (or best-energy, $\mathrm{BE}$ ) $<41 \mathrm{~mJ} / \mathrm{cm}^{2}$ values. Patterning was even demonstrated down to $12 \mathrm{~nm}$ HP with one of CARs (R1UL1) evaluated for their extendibility beyond the $16 \mathrm{~nm}$ HP resolution. $11 \mathrm{~nm}$ HP patterning with some pattern collapse and well resolved patterns down $12 \mathrm{~nm}$ were also demonstrated with another CAR (R15UL1) formulated for $16 \mathrm{~nm}$ HP resolution and below. With such resist it was possible even to obtain a small process window for $14 \mathrm{~nm}$ HP processing with an EL $\sim 8 \%$ $\left(\mathrm{BE} \sim 37 \mathrm{~mJ} / \mathrm{cm}^{2}\right.$, LER $\sim 4.5 \mathrm{~nm}$ ). Though encouraging, fulfilling all of the requirements necessary for high volume production, such as high resolution, low LER, high photon sensitivity (dose), and high exposure latitude (EL) simultaneously still remains challenging below $16 \mathrm{~nm} \mathrm{HP}$.
\end{abstract}

\section{INTRODUCTION}

As we reach a technical impasse with the current lithography manufacturing technology (deep UV immersion lithography), it is necessary to demonstrate whether state-of-the art EUV resist materials that have been investigated for their extendibility towards future technology nodes actually meet the requirements for high volume semiconductor production. Current feature sizes have already only been possible due to clever fabrication strategies such as multiple patterning. The performance of EUV resists is one of the key factors that will ultimately determine the successful introduction of EUV lithography into high volume manufacturing. Fundamental chemical and material properties of the resist and the processes involved in patterning such as acid blur and photon shot noise i.e., determine the ultimate performance of these [1]. Resist performance is defined by the resolution (half-pitch), sensitivity (dose) and the line-edge roughness of the resist. These parameters are nonetheless interconnected, and there is a trade-off relationship among them. The trade-off relationship between the resolution, line-edge roughness and sensitivity (RLS) has been the topic of several studies [2]. Different approaches have been developed in order to account for the RLS trade-off relationship in a meaningful manner and represent the global performance of the material in a straight forward way. A simplified approach from Wallow et al., [1] in which the figure of merit, or so called Z-factor is defined as:

$$
Z=(\text { Sensitivity }) \times(L E R)^{2} \times(H P)^{3}
$$

Extreme Ultraviolet (EUV) Lithography VI, edited by Obert R. Wood II, Eric M. Panning,

Proc. of SPIE Vol. 9422, 94221S · (c) 2015 SPIE · CCC code: 0277-786X/15/\$18 doi: $10.1117 / 12.2085803$ 
In here dose-to-size (or best-energy) represents the sensitivity. This figure of merit is quite useful as it can be determined from easily obtainable data to provide a figure of merit for the overall performance of the resist in question, yet it has its limitations as will be briefly discussed later in this report.

In this study, several chemically-amplified resists (CARs) have been investigated with the aim to resolve patterns down to $11 \mathrm{~nm} \mathrm{HP}$, while primarily focusing on the qualification of $18 \mathrm{~nm}$ and $16 \mathrm{~nm}$ HP resolution resist materials/processes. For the different resists to be commercially relevant for high volume manufacturing they do not only need to be able to resolve the specified HP at a sufficiently low dose (high sensitivity for high throughput) and low LER (low global Z-factor in the end), but they also need to have sufficiently large exposure latitude $(>20 \%)$. This is to allow some flexibility for process instabilities and natural process variation in a production environment. Here we furthermore calculate the exposure latitude (EL) for the different resists at $16 \mathrm{~nm}, 18 \mathrm{~nm}$, and $22 \mathrm{~nm} \mathrm{HP}$ (and below $16 \mathrm{~nm} \mathrm{HP}$ when possible) in order to provide a more complete picture of the performance of the resist in question. This is also important because patterning capabilities of different resists platforms (CARs, inorganic resists among others) have already been demonstrated with the present tools for $16 \mathrm{~nm}$ HP and beyond [3-5], but the full process capabilities of the different resists have seldom been treated in literature. The exposure latitude is calculated from the critical dimension (CD) vs. dose plots. A linear curve is fitted through the points within the $\mathrm{CD}_{\max }$ and $\mathrm{CD}_{\min }$ (critical dimension $\pm 10 \%$ ). We can then extract the $\mathrm{En}\left(\mathrm{CD}_{\max }\right)$ and $\mathrm{EnCD}_{\min }$ (doses at which the minimum and maximum acceptable $\mathrm{CD}$ values are achieved, respectively) from the linear fit. The EL $\pm 10 \%$ is defined as:

$$
E L= \pm\left(E n C D_{\min }-E n C D_{\max }\right) / B E \times 100
$$

For the accurate calculation of the actual exposure latitude EL, only doses for which no pinching, necking or pattern collapse, etc., is observed in the SEM micrographs are included in the analysis.

\section{EXPERIMENTAL DETAILS}

With EUV-IL, a mask with diffraction gratings is illuminated by a spatially coherent beam of EUV light $(\lambda=13.5 \mathrm{~nm})$. First-order diffracted beams overlap at a distance from the mask where the interference pattern is created (periodic aerial image). EUV-IL, with a well-defined aerial image, is thus a simple yet powerful method to create high-resolution periodic nanostructures for the fast and accurate characterization of EUV lithography resists [5]. The resulting aerial image has a period that is half that of the mask grating period when first-order diffraction interference beams are used for patterning. The sinusoidal aerial image is pitch and depth independent. $11 \mathrm{~nm}$ and $8 \mathrm{~nm}$ HP resolutions have been demonstrated before using the EUV interference lithography tool at PSI [5-7]. The EUV-IL tool at PSI therefore provides a low cost and easy access platform for resist screening. This is of particular interest for resist testing for future technology nodes and for academic research activities.

The masks used here consist of HSQ (hydrogen silsesquioxane) gratings fabricated on 100-nm-thick $\mathrm{Si}_{3} \mathrm{~N}_{4}$ membranes (Figure 1a), and a gold photon-stop (Figure 1d). The gratings are designed so that the overlap of higher order diffraction beams with the interference patterns is avoided. All areas outside the gratings on the mask are electroplated with gold to absorb the zeroth-order beam. The masks have been fabricated at the cleanroom facilities of PSI. Figure 1 shows the schematic top-view and cross-section view of A' (as depicted in the schematic) of key steps in fabrication process as adapted from [8]. In the first step, gratings are directly written by an electron beam lithography process (e-beam, Figure $1 \mathrm{~b}$ ). Then, a gold seed layer is deposited by e-beam evaporation and patterned by a lift-off process with PMMA (poly-methyl methacrylate), as shown in Figure 1c. The photon-stop is finally grown by electroplating with gold (Figure 1d). The optimization of the different fabrication steps is very important for the successful fabrication of highresolution transmission gratings with high efficiency and low roughness. In particular, with this process the gratings have extremely low LER, since they are fabricated by direct e-beam writing (i.e., HSQ) without any pattern transfer. 

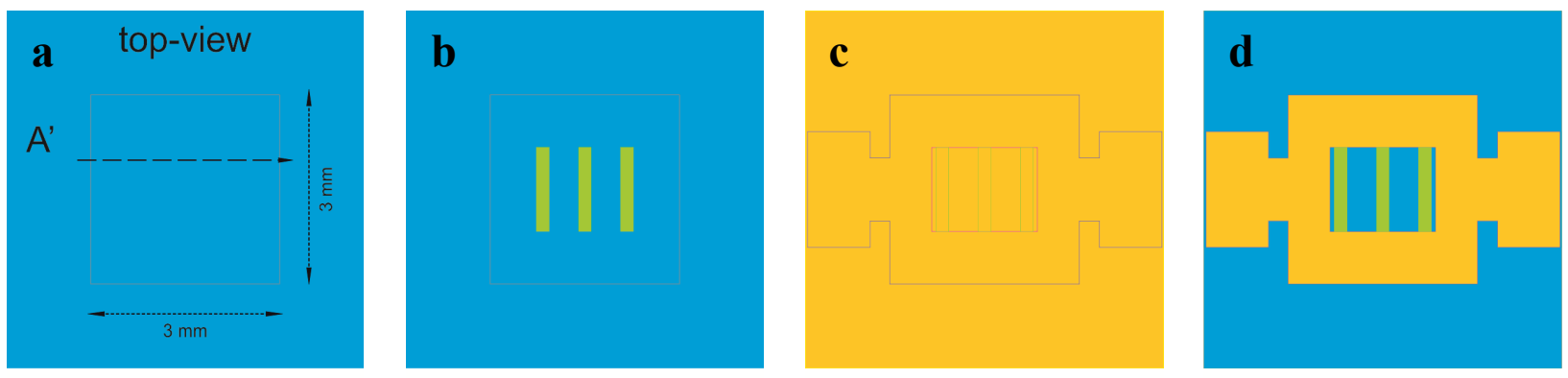

cross-section A'

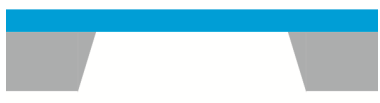

Si

$\mathrm{Si}_{3} \mathrm{~N}_{4}$

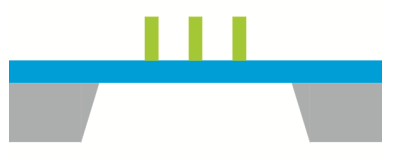

- Si $\mathrm{Si}_{3} \mathrm{~N}_{4}$

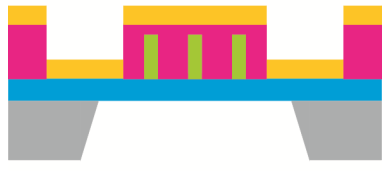

Si

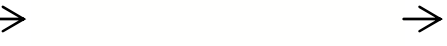

$\rightarrow$

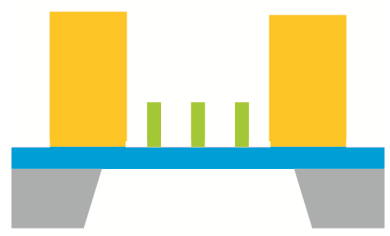

$\mathrm{Si}_{3} \mathrm{~N}_{4} \quad \mathrm{SiO}_{x} \quad \mathrm{Au}$

$\square$ PMMA

Figure 1. Top-view and cross-section view of A' from a) plain nitride membrane, b) HSQ gratings fabricated by e-beam lithography, c) view after gold seed layer evaporation on PMMA for lift-off and d) finished mask membrane mask with electroplated photon-stop.

The dose-on-mask $\left(\mathrm{mJ} / \mathrm{cm}^{2}\right)$ is determined from the measured flux $\left(\mathrm{mJ} \cdot \mathrm{s} / \mathrm{cm}^{2}\right)$ (measured before and after the exposure) and the exposure time (s). Therefore, the tool-factors (ratio between the dose-on-mask and dose-on-wafer) for the fabricated masks were first determined in order to be able to report the corrected dose-on-wafer values as previously reported here [9]. The tool-factors are proportional to the efficiency of the mask. The efficiency of the mask defined as $\eta=D_{O F} / D_{\text {diff }}$ is dependent on the actual grating efficiency (diffraction efficiency) and nitride membrane transparency (transmission efficiency) [8]. Therefore to determine these tool-factors, first an exposure through an open frame at different doses is performed. After development the thicknesses are measured and recorded as a function of the dose-on-mask values and the dose-to-clear through the open frame $\left(D_{O F}\right)$ is determined. Then another dose scan with the same resist is performed using the actual mask for which the tool-factors need to be determined (per HP grating). The resist thickness resulting from the first-order non-interfering diffraction is recorded as a function of dose-on-mask. The dose-to-clear ( $D_{\text {diff }}$, dose to $50 \%$ clearance) is found from the normalized thickness as function of dose-on-mask data when fitted by a dose-response function:

$$
t(D)=t_{0}\left[1+10^{\left(\log _{D_{0}-D}\right) \times p}\right]^{-1}
$$

Where $\mathrm{D}$ is the dose, $t_{0}$ is the maximum thickness difference of unexposed or overexposed resist, $\log _{D_{0}}$ is the dose for $50 \%$ clearance and $p$ is the slope (contrast) $[5,8]$.

In this study we utilized a single mask (M1) that includes $16 \mathrm{~nm}, 18 \mathrm{~nm}, 22 \mathrm{~nm}, 25 \mathrm{~nm}, 35 \mathrm{~nm}$ and $50 \mathrm{~nm}$ HPs for the great majority of the experiments unless otherwise noted. A different mask (M2) that includes HP=11 nm, $12 \mathrm{~nm}, 13$ $\mathrm{nm}, 14 \mathrm{~nm}, 16 \mathrm{~nm}$ and $18 \mathrm{~nm}$ was used to investigate some of the best performing resists at higher resolutions. The toolfactors calculated here for M1 and M2 range from 2.78 to 4.19. The tool-factors are pitch and grating dependent as the efficiency of the different gratings within the same mask can vary greatly.

The SEM images of the resist patterns were obtained using a SEM Carl Zeiss SUPRA 55VP. The in-lens detector with a scanning speed of 10 seconds was used. The acceleration voltage and aperture size was set to $1 \mathrm{kV}$ and $7.5 \mu$ respectively to minimize electron beam damage and get surface information. The magnification and working distance are both kept constant at 400000 and $\sim 3 \mathrm{~mm}$, respectively. The CD and LER values are obtained from the analysis performed with a commercially available modeling software (SuMMIT ${ }^{\circledR}$ ). The LER values correspond to $3 \sigma$ deviation after a certain 
frequency filtering. We note that our current SEM settings and analysis parameters lead to relatively high LER values. A comparison of same structures inspected with a CD SEM at ASML revealed that the values obtained at PSI were high by about $50 \%$.

Twelve different positive-tone CARs (R1, R2, etc.) plus one negative-tone CAR resist were evaluated from different vendors. The underlayer formulations also came from different vendors. Development and other process conditions have been previously optimized elsewhere. The type of resist or underlayer and process conditions (resist and underlayer thickness, post-exposure bake (PEB), post-apply bake (PAB) temperature and process time) were provided or determined by the different resist suppliers. The development was performed in a semiautomatic SUSS Microtech tool that includes a 30 second $2.38 \%$ TMAH dispense step. The development was kept the same for all exposures.

\section{PERFORMANCE OF CHEMICALLY AMPLIFIED RESISTS}

In this section we first report on the overall performance of the different CARs evaluated in this study. As previously stated our main goal is to present an overview of the resist screening results that focuses on their performance at 16 and $18 \mathrm{~nm}$ HPs. Sub-16 nm resolution is still needed nonetheless and this will be addressed later in this report. One single mask (M1) whose layout includes $\mathrm{HP}=50 \mathrm{~nm}, 35 \mathrm{~nm}, 25 \mathrm{~nm}, 22 \mathrm{~nm}, 18 \mathrm{~nm}$, and $16 \mathrm{~nm}$ HP was used for all the exposures in this section. Here we generally only compare the performances for $\mathrm{HP}=16 \mathrm{~nm}, 18 \mathrm{~nm}$, and $22 \mathrm{~nm}$. Using the same mask, SEM conditions and performing the data analysis in the same way allows us to directly compare the different materials while minimizing some of the effects that can introduce some error and variability such as tool stability, roughness of the mask, dose calibration, SEM settings, and analysis parameters.

Figure 2 shows the CD vs. dose, LER vs. dose and LER vs. BE (dose-to-size values for 1:1 L/S patterns.) plots for the different CARs at $\mathrm{HP}=16 \mathrm{~nm}, 18 \mathrm{~nm}$, and $22 \mathrm{~nm}$. Eleven different resists from different vendors are compared. Underlayer 1 (UL1) was used while the resist type changed (UL1 in combination with R1-R7) as can be inferred from the sample names for the first part of this set of experiments. The second part of this set of experiments in utilized a different underlayer (UL2) while the resist type changed again (UL2 in combination with R8-R11).

The dots in the LER vs. BE (bottom) graphs in Figure 2 represents the obtained LER and BE. The solid curves in the same graphs represent the constant Z-factors crossing the dots with minimum Z-factors obtained at the corresponding HPs. The R1UL exposure was repeated at 3 different times. The calculated $Z$ values for this R1UL1 were obtained from the average LER and BE values from these three exposures. Table 1 furthermore summarizes all the obtained information from the plotted data such as the BE, LER, actual exposure latitude and Z-factors.

All resists show well resolved patterning down to $16 \mathrm{~nm}$ HP with EL > 10\% with the exception of R7UL1 and R11UL2. Though both of these resists can be resolved down to $16 \mathrm{~nm}$ they show no EL as pattern collapse is quite prevalent, especially at smaller pitches. As can be seen in Figure 2 and Table 1 the exposure latitude generally decreases with decreasing HP. The dose-to-size values range from $28-41 \mathrm{~mJ} / \mathrm{cm}^{2}$ and the LER values range from 2.5 to $5.5 \mathrm{~nm}$.

The Z-factor as a figure of merit, though useful, it only gives us part of the information needed to determine whether a resist will be interesting, in particular for high volume manufacturing. This is because even though patterning may be possible with sufficiently low LER values and at low doses for a particular HP of interest (which would be ultimately indicated by an excellently low Z-factor), the resist might yet not have any exposure latitude or sufficiently wide exposure latitude for our purposes. Typically, pinching, necking, bridging, and pattern collapse effectively reduce the process window for which the resist is usable. Therefore, even though a resist may initially look promising due to its low Z-factor, to be commercially relevant for high volume manufacturing it also has to perform well when there is variation. All of the resists tested here in fact show low Z-factors $<5 \mathrm{E}-8 \mathrm{~nm}^{3} \mathrm{~mJ}$ for all half-pitches down to $16 \mathrm{~nm}$ and yet for some resist such as R10UL2 the exposure latitude is only $\sim 12 \%$ at $16 \mathrm{~nm} \mathrm{HP}$. 
$\mathrm{HP}=16 \mathrm{~nm}$
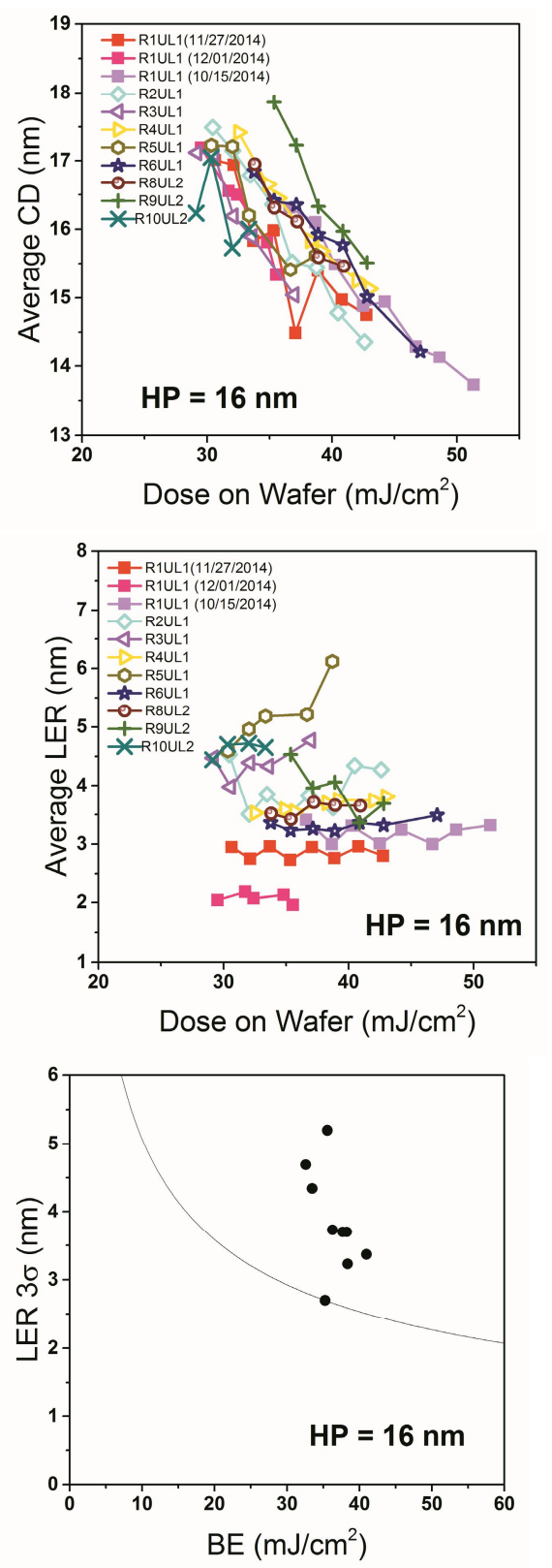

$\mathrm{HP}=18 \mathrm{~nm}$
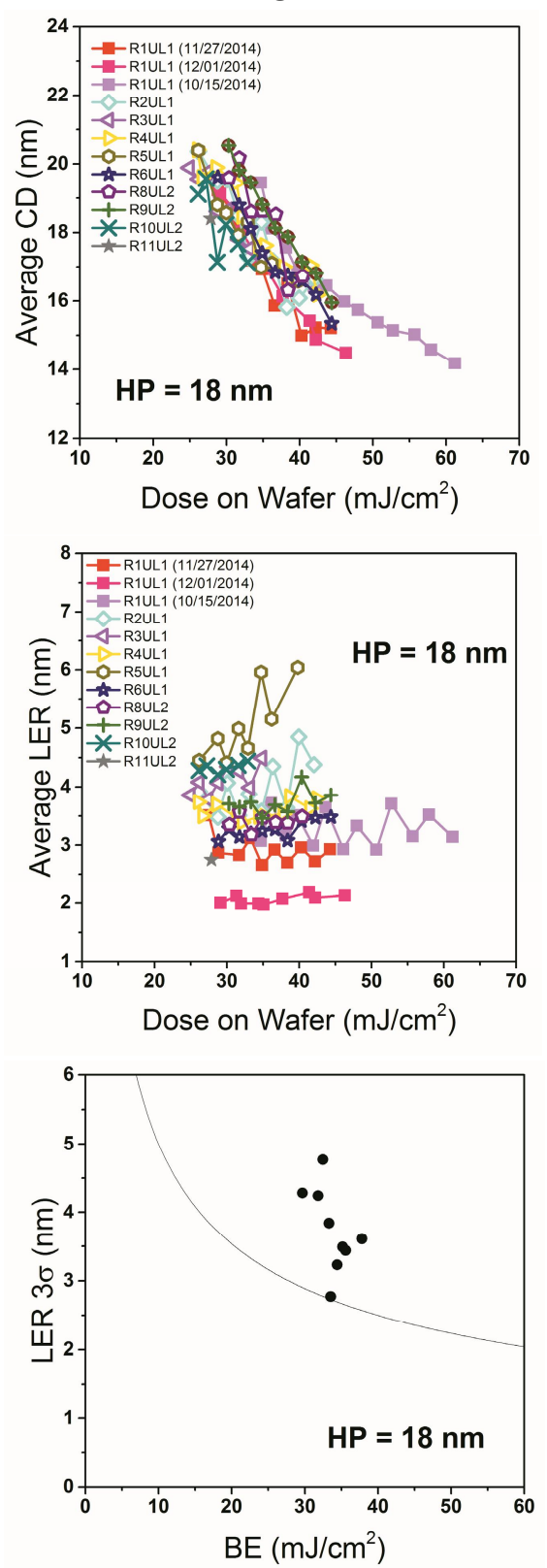

$\mathrm{HP}=22 \mathrm{~nm}$
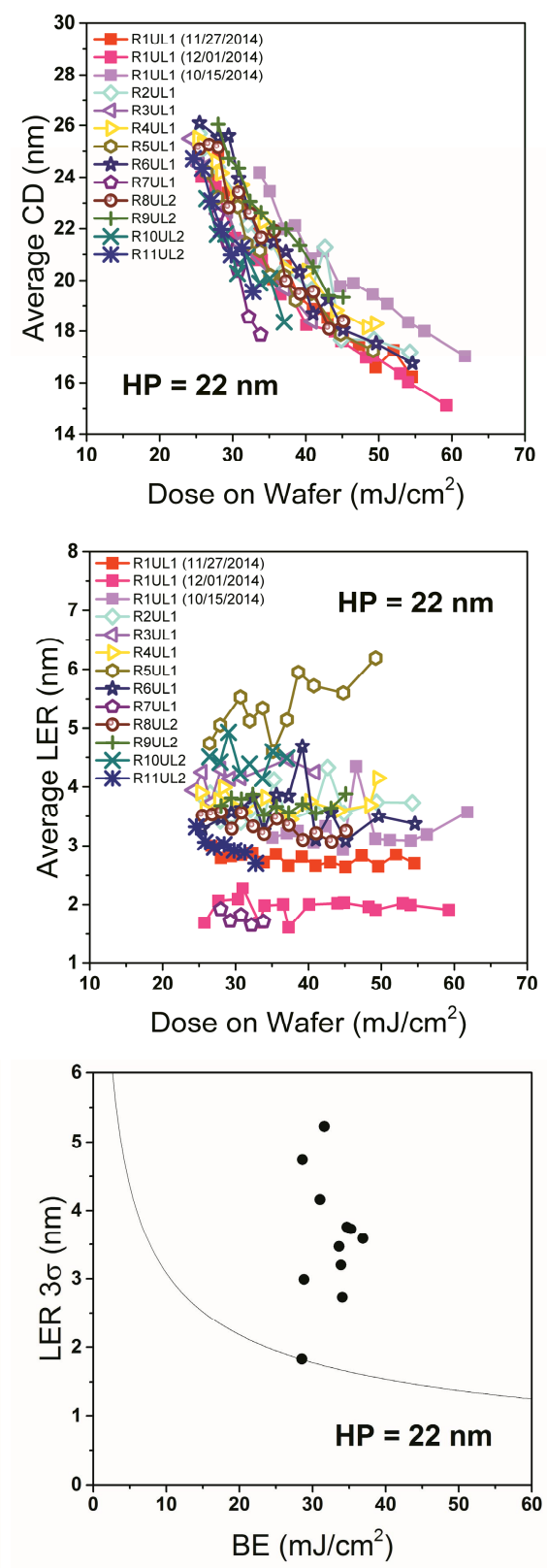

Figure 2. CD vs. dose (top), average LER vs. dose (center) and LER vs. BE (bottom) curves obtained with different chemically amplified resists for $H P=16 \mathrm{~nm}$ (left), $18 \mathrm{~nm}$ (middle) and $22 \mathrm{~nm}$ (right). The dots in the LER vs. BE (bottom) graphs represents the obtained LER and dose-to-size values for 1:1 L/S patterns. The solid curves in the same graphs represent the constant Z-factors crossing the dots with minimum Z-factors at the corresponding HPs. M1 was used for all exposures used to obtain the data. 
Table 1. BE, EL, LER and Z-factors for the different CAR resists tested for $H P=16 \mathrm{~nm}, 18 \mathrm{~nm}$, and $22 \mathrm{~nm}$. Some of the most performing resists are highlighted in bold.

\begin{tabular}{|c|c|c|c|c|c|c|c|c|c|c|c|c|c|c|}
\hline \multicolumn{5}{|c|}{ HP: 16 nm } & \multicolumn{5}{|c|}{ HP: $18 \mathrm{~nm}$} & \multicolumn{5}{|c|}{ HP: $22 \mathrm{~nm}$} \\
\hline Name & $\begin{array}{l}\text { BE } \\
(\mathrm{mJ} / \mathrm{cm} 2)\end{array}$ & EL (\%) & LER $(\mathrm{nm})$ & Z-factor & Name & \begin{tabular}{|l}
$\mathrm{BE}$ \\
$(\mathrm{mJ} / \mathrm{cm} 2)$
\end{tabular} & EL (\%) & LER $(\mathrm{nm})$ & Z-factor & Name & \begin{tabular}{|l|}
$\mathrm{BE}$ \\
$(\mathrm{mJ} / \mathrm{cm} 2)$
\end{tabular} & EL (\%) & LER $(\mathrm{nm})$ & Z-factor \\
\hline R1UL1(average) & $35+-1.76$ & 24.66 & 2.7 & $1.05 \mathrm{E}-08$ & R1UL1(average) & $33+-2.41$ & 29.18 & \begin{tabular}{|l|}
2.77 \\
\end{tabular} & $1.50 \mathrm{E}-08$ & R1UL1(average) & $34+-3.4$ & 33 & 2.7 & $2.71 \mathrm{E}-08$ \\
\hline R2UL1 & 36.3 & 32.52 & 3.73 & 2.07E-08 & R2UL1 & 33.3 & 28.44 & 3.84 & $2.86 \mathrm{E}-08$ & R2UL1 & 33.63 & 34.22 & 3.47 & $4.31 \mathrm{E}-08$ \\
\hline R3UL1 & 33.48 & 23.23 & 4.34 & $2.58 \mathrm{E}-08$ & R3UL1 & 31.83 & 28.64 & 4.24 & $3.34 \mathrm{E}-08$ & R3UL1 & 31.03 & 30.25 & 4.16 & $5.72 \mathrm{E}-08$ \\
\hline R4UL1 & 38.25 & 27.36 & 3.7 & 2.14E-08 & R4UL1 & 35.17 & 36.64 & 3.49 & $2.50 \mathrm{E}-08$ & R4UL1 & 34.71 & 33.85 & 3.76 & 5.23E-08 \\
\hline R5UL1 & 35.58 & 23.45 & 5.2 & $3.94 \mathrm{E}-08$ & R5UL1 & 32.48 & 29.24 & 4.77 & $4.31 \mathrm{E}-08$ & R5UL1 & 31.62 & 33.57 & 5.23 & $9.21 \mathrm{E}-08$ \\
\hline R6UL1 & 38.35 & 33.33 & 3.23 & $1.64 \mathrm{E}-08$ & R6UL1 & 34.44 & 34.68 & 3.23 & 2.10E-08 & R6UL1 & 35.25 & 26.36 & 3.73 & $5.22 \mathrm{E}-08$ \\
\hline & & & & & & & & & & R7UL1 & 28.54 & 11.29 & 1.83 & $1.02 \mathrm{E}-08$ \\
\hline R8UL2 & 37.69 & 18.89 & 3.7 & $2.11 \mathrm{E}-08$ & R8UL2 & 35.59 & 21.75 & 3.44 & $2.46 \mathrm{E}-08$ & R8UL2 & 33.9 & 32.4 & 3.2 & $3.70 \mathrm{E}-08$ \\
\hline R9UL2 & 40.96 & 17.09 & 3.37 & $1.91 \mathrm{E}-08$ & R9UL2 & 37.81 & 31.36 & 3.61 & $2.87 \mathrm{E}-08$ & R9UL2 & 36.9 & 31.38 & 3.59 & 5.06E-08 \\
\hline R10UL2 & 32.58 & 12.91 & 4.69 & $2.94 \mathrm{E}-08$ & R10UL2 & 29.68 & 22.73 & 4.28 & $3.17 \mathrm{E}-08$ & R10UL2 & 28.62 & 27.31 & 4.74 & $6.85 \mathrm{E}-08$ \\
\hline & & & & & & & & & & R11UL2 & 28.84 & 23.8 & 2.99 & 2.75E-08 \\
\hline
\end{tabular}

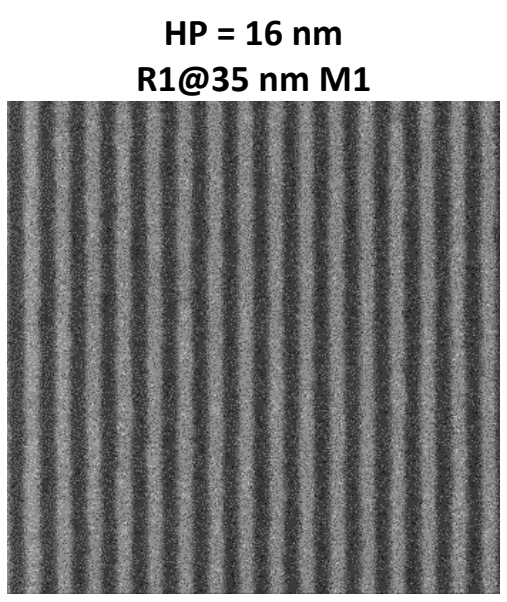

$\mathrm{HP}=25 \mathrm{~nm}$

R1@35 nm M1

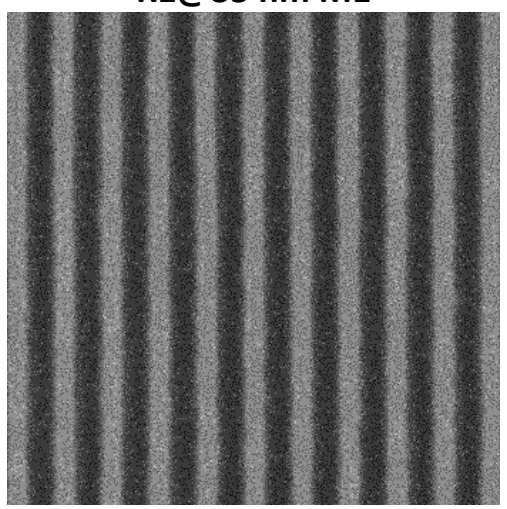

$\mathrm{HP}=18 \mathrm{~nm}$

R1@35 nm M1

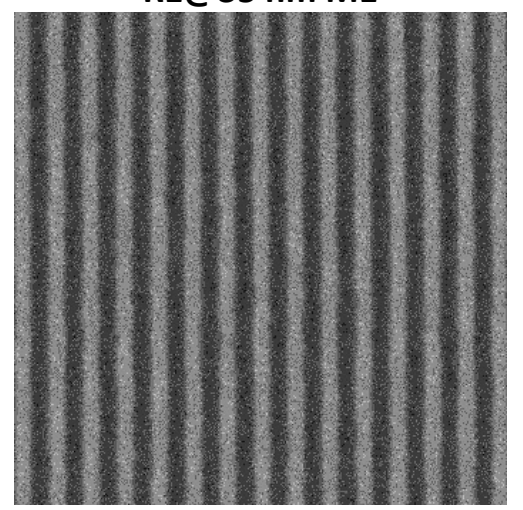

$\mathrm{HP}=35 \mathrm{~nm}$

R1@35 nm M1

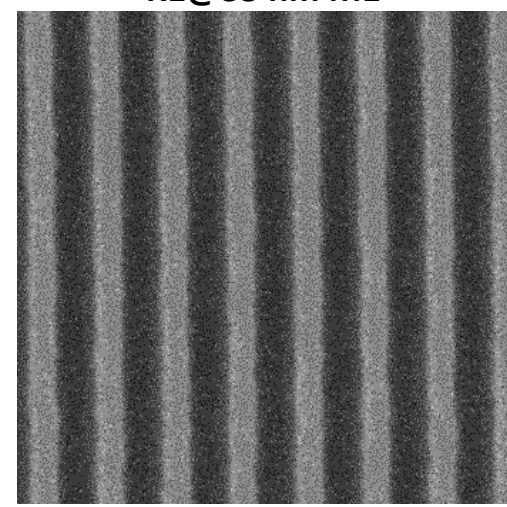

$\mathrm{HP}=22 \mathrm{~nm}$

R1@35 nm M1

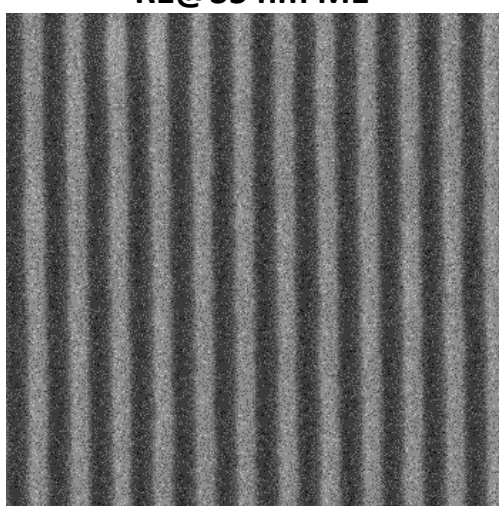

$\mathrm{HP}=50 \mathrm{~nm}$

R1@35 nm M1

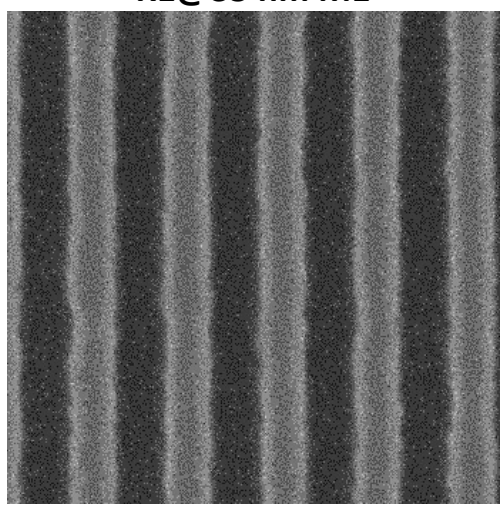

Figure 3. SEM images for resist (R1UL1) for different half-pitches from $16 \mathrm{~nm}$ to $50 \mathrm{~nm}(1: 1 \mathrm{~L} / \mathrm{S}$ patterns). The pictures show SEM images obtained using M1 (R1 with a thickness of $35 \mathrm{~nm}$ ).

As previously mentioned, and as can be seen in Figure 2 the R1UL exposure was repeated at 3 different times. It is clear from the graphs that there is a certain degree of variation from exposure to exposure which could come from the IL tool, the SEM conditions, or even resist aging. Figure 3 shows an example of the different SEM images for $16 \mathrm{~nm}$ to $50 \mathrm{~nm}$ 
HPs (for line-space 1:1 L/S patterns) obtained from exposures using this highly performing resists (R1UL1) as an example. The performance (low $\mathrm{Z} \sim 1 \mathrm{e}-8 \mathrm{~nm}^{3} \mathrm{~mJ}$, high EL $20-35 \%$, low $\mathrm{BE} \sim 35 \pm 1.76 \mathrm{~mJ} / \mathrm{cm}^{2}$ and low LER 2.1-3.13 nm) of this resist and UL combinations is excellent down to $16 \mathrm{~nm} \mathrm{HP}$. Figure 4 shows the corresponding $\mathrm{CD}$ and LER vs. dose plots for $16 \mathrm{~nm}$ to $50 \mathrm{~nm} \mathrm{HP}$.
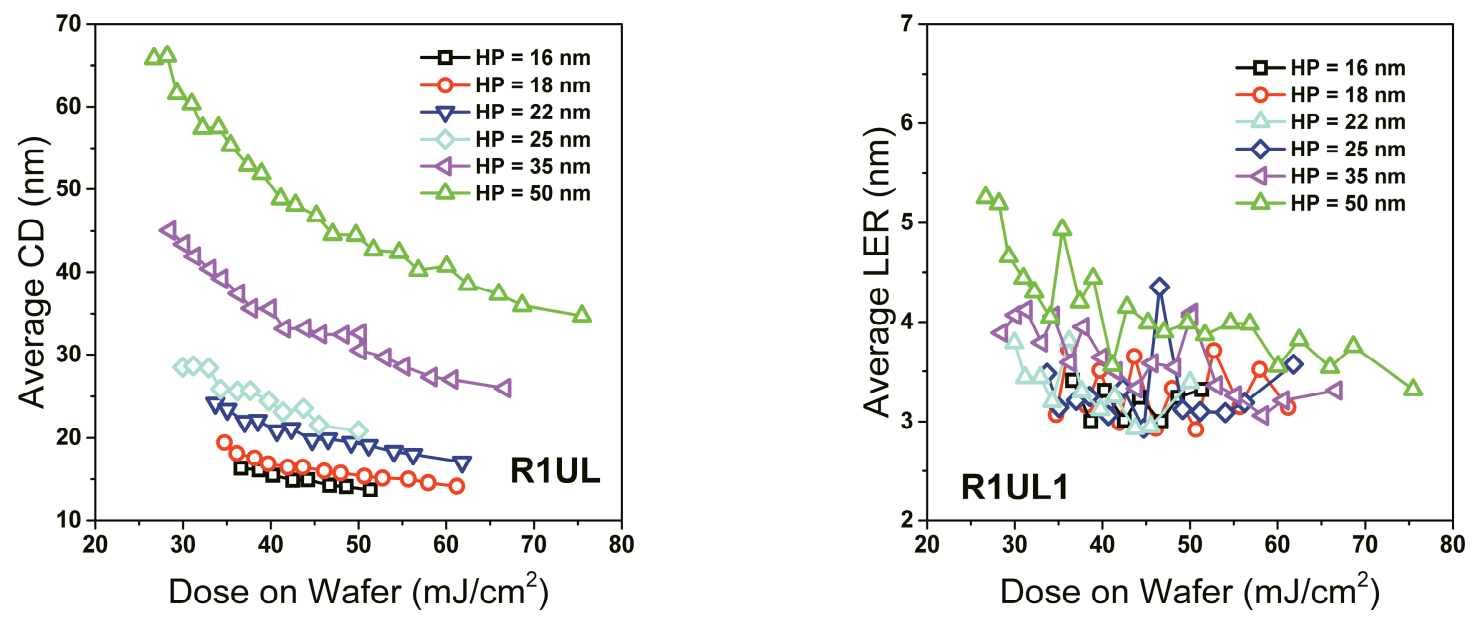

Figure 4. CD and LER vs. dose plots for R1UL1 (R1 with $35 \mathrm{~nm}$ thickness) when exposed using M1 for $16 \mathrm{~nm}$ to $50 \mathrm{~nm}$ HPs.

In order to explore this RLS trade-off relationship, other available resist processes have been studied before in literature such as the use of underlayers and even bottom layers (BL, underneath the underlayer materials) [10]. In here we investigated two different underlayer (plus bottom layer combinations) materials while keeping the same resist (R1) constant. Figure 5 shows the $\mathrm{CD}$ vs. dose and $\mathrm{CD}$ vs. LER plots for exposures using the highly performing resist R1(and UL1) while the UL changed (BL1 was kept constant when a different UL was used). We performed the exposures on the same day with the same mask including a test with R1UL1 for comparison. Table 2 summarizes the obtained information from the plotted data such as the BE, LER, and EL. It is worth noting first of all, that when a bottom layer was used, the SEM picture contrast of the exposed patterns was extremely poor (Figure 6). This is likely the cause for the broadly scattered CD and LER values found with the commercial modeling software. For this reason, though LER values are here reported we will not attempt to compare these values among different samples. In general, the BE shifted towards lower values (i.e., from 37.7 to $31.3 \mathrm{~mJ} / \mathrm{cm}^{2}$, for $\mathrm{HP}=16 \mathrm{~nm}$ ) for all HPs when using either of the UL+BL1 combinations in comparison to the reference R1UL1 exposure. This is consistent with previous reports where the same type of underlayers have been found to provide better sensitivities enhancing the performance of the resist [11].

New resists chemistries and architectures have been explored in order to overcome the RLS trade-off limitations and extend EUV resists to future nodes. With decreasing HP pattern collapse is promoted due to the high aspect ratios which limit the resolution that can be achieved with CARs. With decreasing HPs, pattern collapse becomes the limiting factor. Underlayers or adhesion layers have been widely utilized in order to minimize pattern collapse at high resolutions [10]. Nevertheless $16 \mathrm{~nm}$ HP were possible to be resolved when UL5 was utilized, pattern collapse was the main mode of failure for this resist $+\mathrm{UL}(+\mathrm{BL}$ combination). CD or LER values could therefore not be determined using the commercial modeling software for this HP. UL4+BL1 on the other side produced similar results in terms of exposure latitude for HP = $22 \mathrm{~nm}$ and $16 \mathrm{~nm}$, but for HP $18 \mathrm{~nm}$ it improved in comparison to the standard R1UL1 process (from $25 \%$ to $36 \%)$. 

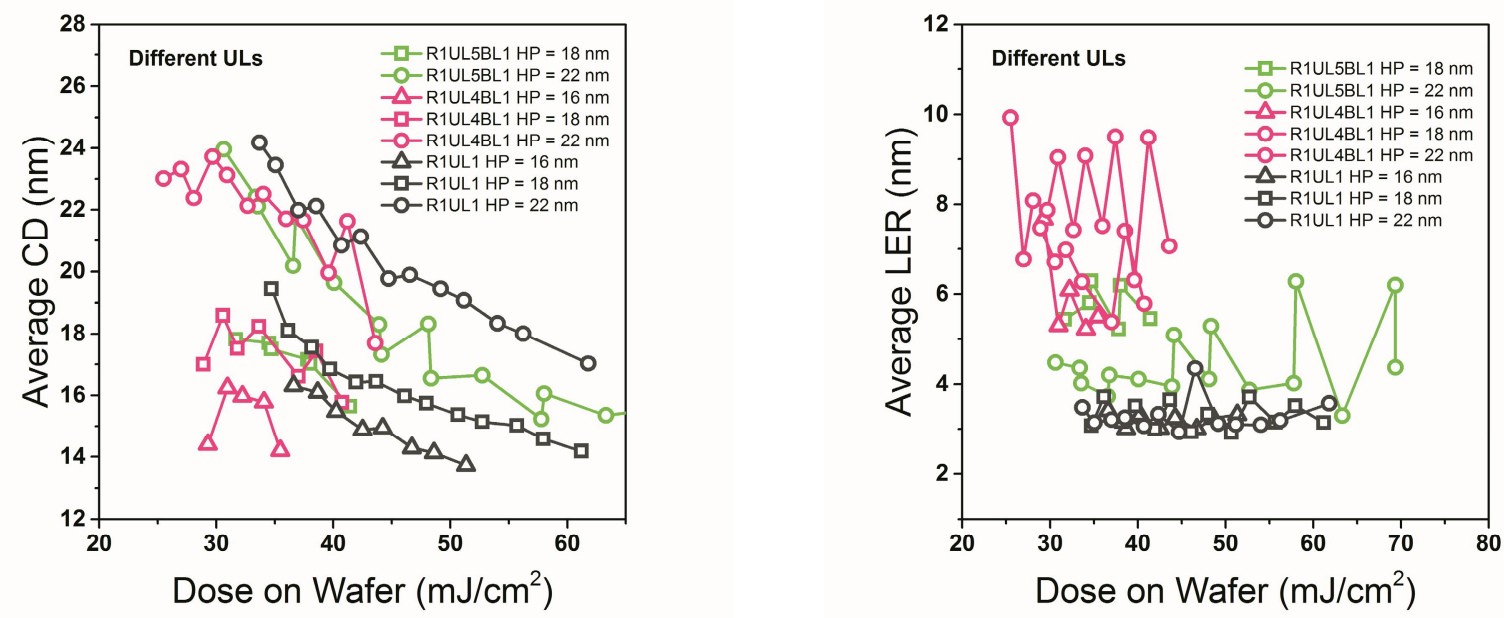

Figure 5. CD and LER vs. dose plots for R1 as the UL changed (BL1 constant) when exposed using M1 for $16 \mathrm{~nm}$, $18 \mathrm{~nm}$ and $22 \mathrm{~nm}$ HPs. R1UL1 exposure performed on the same day was also included for comparison.
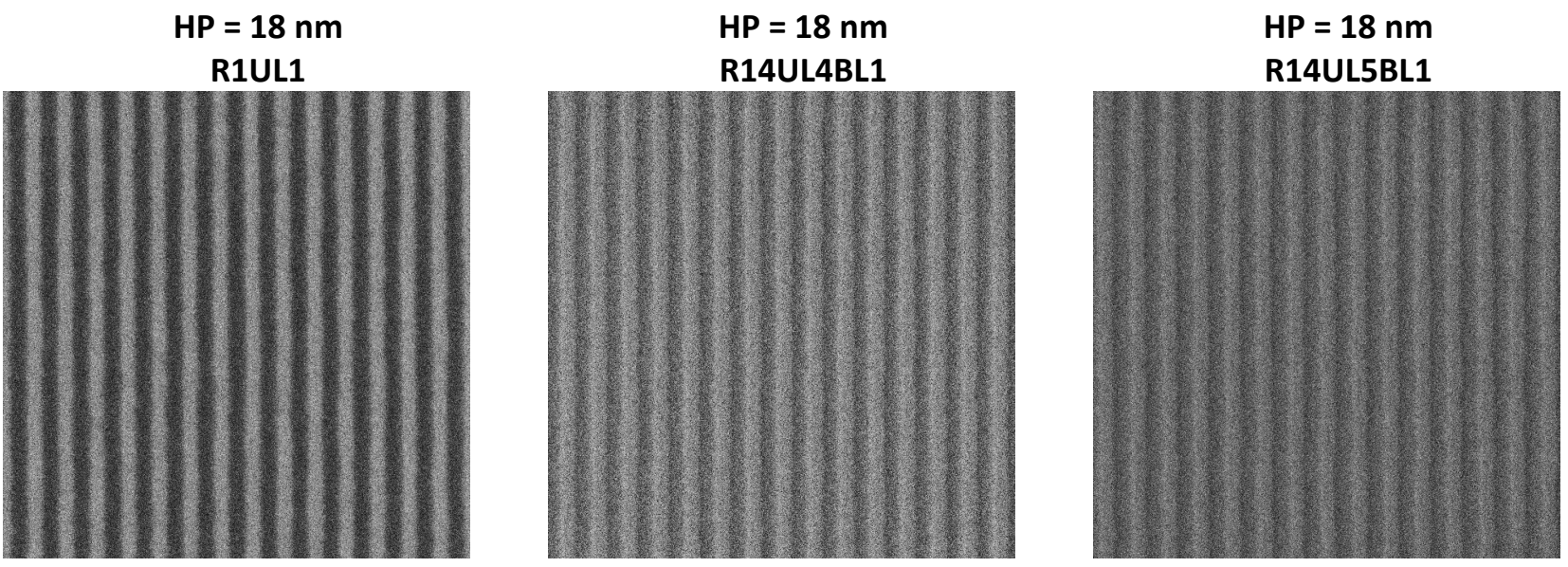

Figure 6. SEM images for resist (R1) and different ULs for HP $=18 \mathrm{~nm}(1: 1 \mathrm{~L} / \mathrm{S}$ patterns). The pictures show SEM images obtained from exposures using M1 (R1 with a thickness of $35 \mathrm{~nm}$ ).

Table 2. BE, EL and LER for the different UL + BL1 materials tested while keeping R1 constant (BL1 also constant when used) for $\mathrm{HP}=16 \mathrm{~nm}, 18 \mathrm{~nm}$, and $22 \mathrm{~nm}$.

\begin{tabular}{|c|c|c|c|c|c|c|c|c|c|c|c|}
\hline \multicolumn{4}{|c|}{ HP: $16 \mathrm{~nm}$} & \multicolumn{4}{|c|}{ HP: $18 \mathrm{~nm}$} & \multicolumn{4}{|c|}{ HP: $22 \mathrm{~nm}$} \\
\hline Name & \begin{tabular}{|l|}
$\mathrm{BE}$ \\
$(\mathrm{mJ} / \mathrm{cm} 2)$
\end{tabular} & EL (\%) & LER $(\mathrm{nm})$ & Name & $B E(\mathrm{~mJ} / \mathrm{cm} 2)$ & EL (\%) & $\operatorname{LER}(\mathrm{nm})$ & Name & \begin{tabular}{|l}
$\mathrm{BE}$ \\
$(\mathrm{mJ} / \mathrm{cm} 2)$
\end{tabular} & EL $(\%)$ & LER $(\mathrm{nm})$ \\
\hline R1UL1 & \begin{tabular}{|r|}
37.72 \\
\end{tabular} & 20.87 & 3.13 & R1UL1 & $\begin{array}{r}6.94 \\
\end{array}$ & 25.3 & 3.5 & R1UL1 & 38.78 & 33.41 & 3.13 \\
\hline & & & & R1UL5BL1 & 32.56 & 26.05 & 5.56 & R1UL5BL1 & 34.16 & 26.65 & 3.96 \\
\hline R1UL4BL1 & 31.31 & 19.79 & 5.52 & R1UL4BL1 & 32.27 & 36.5 & 6.8 & R1UL4BL1 & 35.01 & 34.09 & 8.29 \\
\hline
\end{tabular}


Another approach widely utilized as a pattern collapse mitigation strategy is simply the use of thinner layers of resist. Though resist thickness reduction is still generally an effective way to prevent pattern collapse, this nevertheless has been found to typically increase the LER significantly [5]. Also, etching resistance is another important factor that needs to be addressed for the development of resists materials when such measures are needed. Figure 7 shows the CD vs. dose and CD vs. LER plots for exposures using the same CAR resist R14 and underlayer UL1 but changing the resist thickness from 35 to $40 \mathrm{~nm}$. An exposure with R1UL1 was also performed on the same day with the same mask M1 for comparison, but as this is a negative-tone resist it will not be plotted in the same graph. Table 3 summarizes the obtained information from the plotted data such as the BE, LER and EL. It is worth noting that though it is possible to resolve patterns down to $16 \mathrm{~nm}$ HP resolution, the thick resist does not show any exposure latitude at $\mathrm{HP}=16 \mathrm{~nm}$. EL furthermore decreased quite significantly from $23 \%$ to $7 \%$ as the thickness increased from $35 \mathrm{~nm}$ to $40 \mathrm{~nm}$. The LER values were found to be comparable for all HPs. With the exception to the BE improvement when thinner resist is used, the overall performance (EL, LER and BE) of this resist (thick or thin) still does not compare to the highly performing resist R1UL1 except for HP $22 \mathrm{~nm}$ at which thin R14UL1's performance is comparable just with slightly better lower best energies $\left(\mathrm{BE} \sim 27\right.$ vs. $\left.30 \mathrm{~mJ} / \mathrm{cm}^{2}\right)$.
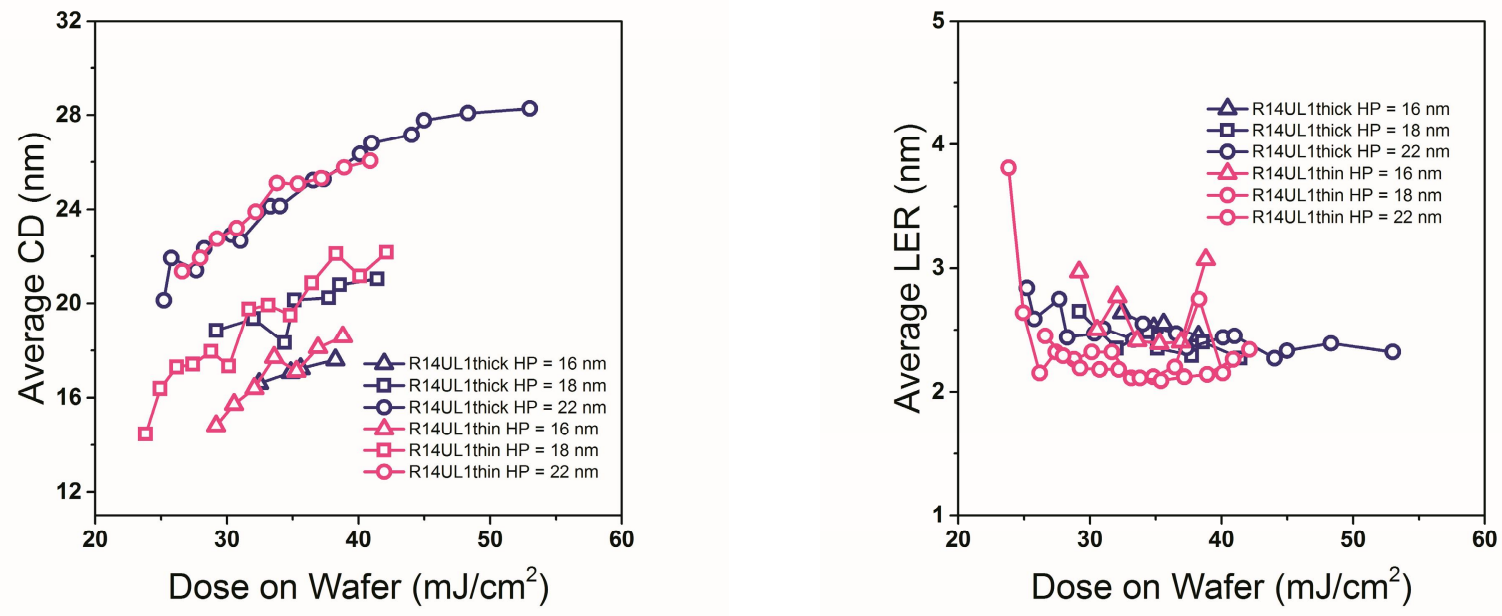

Figure 7. CD and LER vs. dose plots when the same CAR resist (same UL also) is used at two different thicknesses $(35 \mathrm{~nm}$ and $40 \mathrm{~nm}$, thin and thick resist respectively) were tested for $\mathrm{HP}=16 \mathrm{~nm}, 18 \mathrm{~nm}$, and $22 \mathrm{~nm}$.

\begin{tabular}{|c|c|c|c|c|c|c|c|c|c|c|c|}
\hline \multicolumn{4}{|c|}{ HP: 16 nm } & \multicolumn{4}{|c|}{ HP: $18 \mathrm{~nm}$} & \multicolumn{4}{|c|}{ HP: 22 nm } \\
\hline Name & \begin{tabular}{|l} 
BE \\
$(\mathrm{mJ} / \mathrm{cm} 2)$
\end{tabular} & EL (\%) & LER (nm) & Name & $\mathrm{BE}(\mathrm{mJ} / \mathrm{cm} 2)$ & EL (\%) & LER $(\mathrm{nm})$ & Name & $\begin{array}{l}\mathrm{BE} \\
(\mathrm{mJ} / \mathrm{cm} 2)\end{array}$ & EL (\%) & LER $(\mathrm{nm})$ \\
\hline R1UL1 & \begin{tabular}{|r|}
33.71 \\
\end{tabular} & \begin{tabular}{|r|}
17.85 \\
\end{tabular} & 2.1 & R1UL1 & \begin{tabular}{|r|}
32.12 \\
\end{tabular} & 29.43 & 1.99 & R1UL1 & \begin{tabular}{|r|}
30.53 \\
\end{tabular} & 33.91 & 2.15 \\
\hline R14UL1thin & 28.73 & 19.74 & 2.54 & R14UL1thin & 26.3 & 23.78 & 2.4 & R14UL1thin & 26.85 & 34.14 & 2.68 \\
\hline R14UL1thick & 31.16 & 0 & 2.61 & R14UL1thick & 28.69 & 7.215058 & 2.26 & R14UL1thick & 26.76 & 26.18 & 2.43 \\
\hline
\end{tabular}

Table 3. BE, EL, and LER when the same CAR resist (same UL also) is used at two different thicknesses (35 $\mathrm{nm}$ and $40 \mathrm{~nm}$, thin and thick resist respectively) were tested for $H P=16 \mathrm{~nm}, 18 \mathrm{~nm}$, and $22 \mathrm{~nm}$. R1UL1 exposure experimental results are also included in this table for comparison. The exposures were performed in the same day with the same mask M1.

\section{EUV RESISTS TOWARDS 11 NM HP}

In order to further investigate if some of the highly performing resists and UL combinations could be promising for HPs below $16 \mathrm{~nm}$, R1UL1 resist was tested with a reduced thickness from $35 \mathrm{~nm}$ to $30 \mathrm{~nm}$ as this typically improves the exposure latitude even if it is at the expense of a slightly higher LER [5]. R1UL1 was therefore tested with a different 
mask M2 as thi includes $\mathrm{HP}=14 \mathrm{~nm}, 13 \mathrm{~nm}, 12 \mathrm{~nm}, 11 \mathrm{~nm}$ and overlaps with HP $16 \mathrm{~nm}$ and $18 \mathrm{~nm}$ of M1. Figure 8 shows an example of the different SEM images for $14 \mathrm{~nm}$ to $11 \mathrm{~nm}$ HPs (for line-space 1:1 L/S patterns) obtained from exposures using the same highly performing resists, UL combinations (R1UL1).

\section{$\mathrm{HP}=11 \mathrm{~nm}$}

R1@30 nm M2

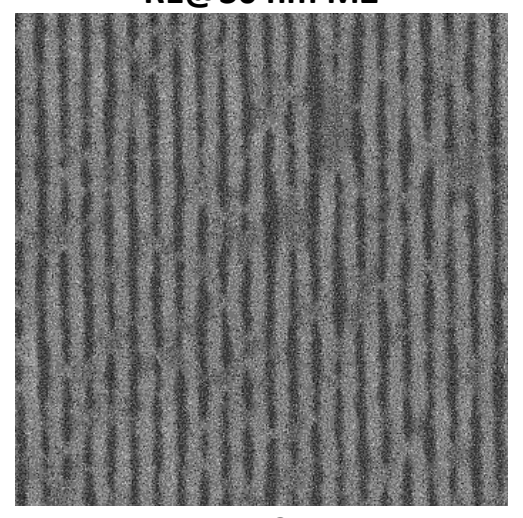

$\mathrm{HP}=13 \mathrm{~nm}$

R1@30 nm M2

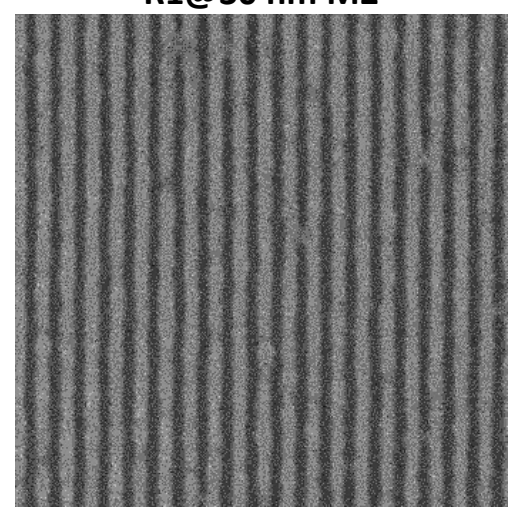

$\mathrm{HP}=12 \mathrm{~nm}$

R1@30 nm M2

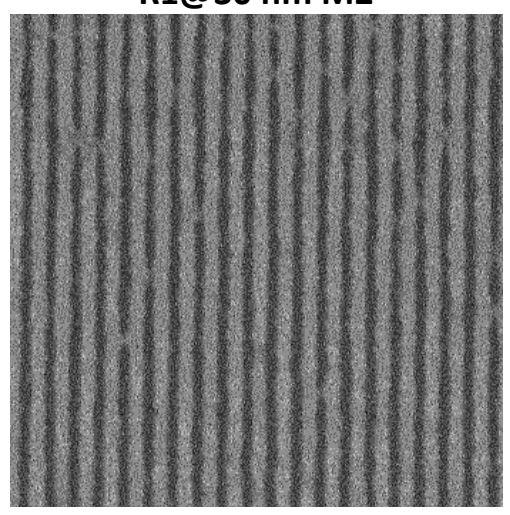

$\mathrm{HP}=14 \mathrm{~nm}$

R1@30 nm M2

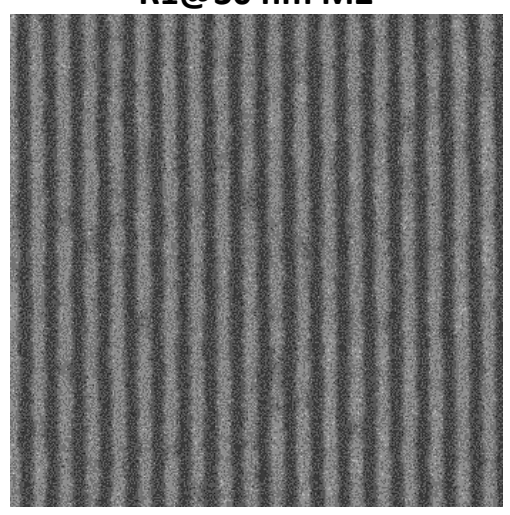

Figure 8. SEM images for resist (R1UL1) for $11 \mathrm{~nm}$ to $14 \mathrm{~nm}$ HPs (for line-space 1:1 LS patterns). The pictures show SEM images obtained using M2 that includes HPs $<16 \mathrm{~nm}$ (and a resist R1 thickness $=30 \mathrm{~nm}$ ).

Modulation can only be observed at HP $11 \mathrm{~nm}$, but resolved patterns can be obtained already at HP = $12 \mathrm{~nm}$ with slight pattern collapse and bridging. For HP $=14 \mathrm{~nm}$ we have well-resolved patterns without pattern collapse but pinching is evident. This pinching means that we have no exposure latitude for this HP nonetheless. Figure 9 shows the CD and LER vs. dose plots for the HPs for which data analysis was possible (HP $=14,15$ and $16 \mathrm{~nm})$ and for comparison the overlapping $\mathrm{HP}=16 \mathrm{~nm}$ tested with $\mathrm{M} 1$ on the same date with the same R1UL1 but with thicker resist R1 ( $35 \mathrm{~nm}$ vs. $30 \mathrm{~nm}$ ). The EL improved slightly from 26 to 28\% but the LER values are comparable for this exposure $\sim 3.5 \mathrm{~nm}$. Though the LER does not significantly increase for $16 \mathrm{~nm}$ HP resolution as the resist thickness is decreased (Figure 8), it is clear that for 14 and $13 \mathrm{~nm}$ HP the LER reaches an unacceptable value of $>30 \%$ of the CD values and increases monotonically as the HP decreases from $16 \mathrm{~nm}$ to $13 \mathrm{~nm}$ HP. Below $13 \mathrm{~nm}$ HP significant bridging and necking was observed and therefore CD and LER values could not be accurately obtained and therefore they are not plotted. Nonetheless all these problems, it is clear that this resist in particular is highly performing for a wide range of HPs down to $16 \mathrm{~nm}$. Below $16 \mathrm{~nm}$ other pattern collapse mitigation strategies need to be explored to be able to reach 11 $\mathrm{nm}$. Though R1UL1 can resolve patterns down to $12 \mathrm{~nm}$ HP, other resists tested here might be able to achieve this as well after some optimization which will be address in the near future. This is the immediate future goal for this project, to test the extendibility of the highly performing resist for $16 \mathrm{~nm}$ down to $11 \mathrm{~nm}$ resolution. 

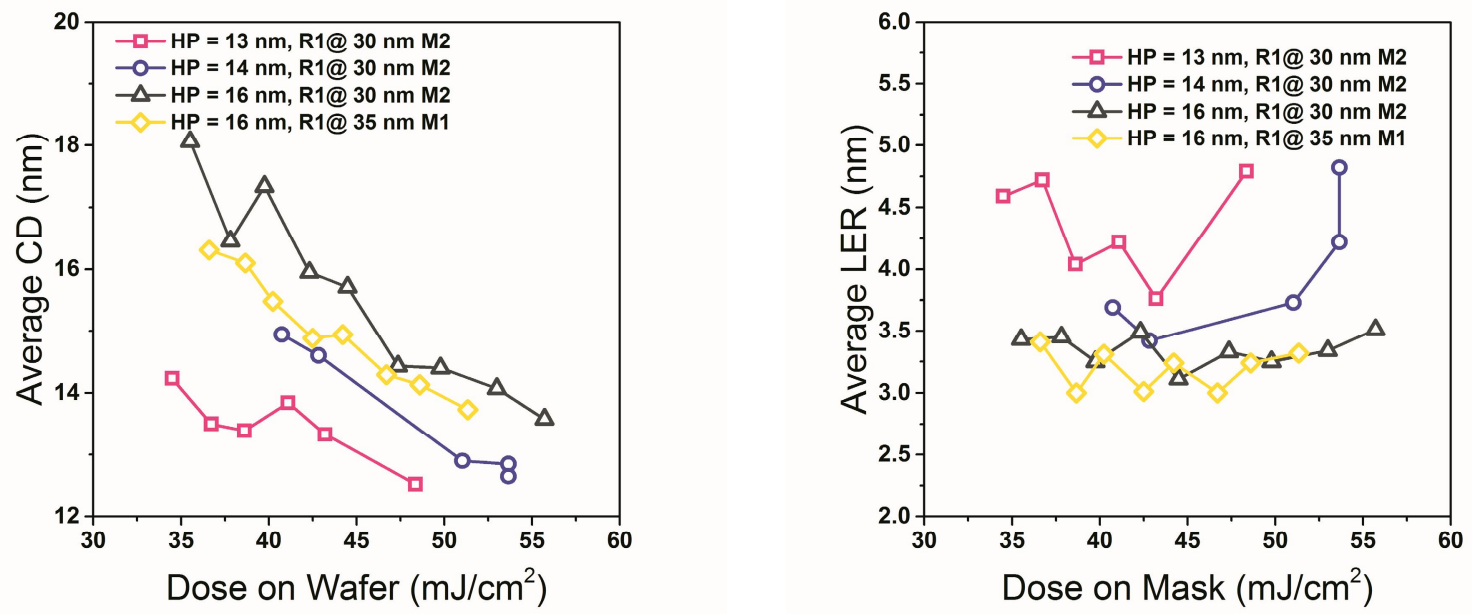

Figure 9. CD and LER plots for the HPs $\leq 16 \mathrm{~nm}$ for which data analysis was possible $(H P=14,15$ and $16 \mathrm{~nm})$ when using R1with a thickness of $30 \mathrm{~nm}$ and M2. For comparison the overlapping HP = 16 $\mathrm{nm}$ tested with M1 on the same date with the same R1UL1 but with thicker resist R1 (35 nm vs. $30 \mathrm{~nm})$ is also plotted.

We furthermore tested with M2 a different state of the art-resist (R15UL1) designed for $16 \mathrm{~nm} \mathrm{HP}$ resolution and below. Figure 11 shows an example of the different SEM images for $14 \mathrm{~nm}$ to $11 \mathrm{~nm}$ HPs (for line-space 1:1 L/S patterns) obtained from this exposure. With this resist, we can resolve patterns with slight pattern collapse at $11 \mathrm{~nm} \mathrm{HP.} 12 \mathrm{~nm} \mathrm{HP}$ is already well resolved and no bridging is observed. For HP $=13 \mathrm{~nm}$ we have well resolved patterns without pattern collapse but pinching limits the EL at this HP which would limit its performance in a production setting. Even more promising is the fact that at $14 \mathrm{~nm}$ HP we find a range of doses for which no pinching, bridging or pattern collapse is observed as can be seen in Table 4. However small, we have a small process window at HP $=14 \mathrm{~nm}$ for which the exposure latitude was found to be about $8 \%$. At $14 \mathrm{~nm}$ HP the LER nonetheless reaches a value of $>35 \%$ of the CD $(4.87 \mathrm{~nm})$ which is again above the $20 \%$ acceptable value. Nonetheless, this elevated LER values also originate as a result of the bad SEM contrast when extremely thin layers of resist are used for imaging $(25 \mathrm{~nm})$. Table 4 also shows the BE, EL and LER values for the reference resist (R1UL1) at $30 \mathrm{~nm}$ thickness for comparison. The exposures were performed on the same day with the same mask M2. These examples serve to show some of the problems faced when trying to improve the resolution of CARs while simultaneously improving the LER and maintaining a wide EL. As the resolution increases pattern collapse becomes a major problem and limitation. Reducing the resist thickness is not the best solution for improving the exposure latitude of the resist as the LER can suffer quite greatly. Other pattern collapse mitigation strategies need to be pursued in order to address this issue. 
R1@25 nm M2

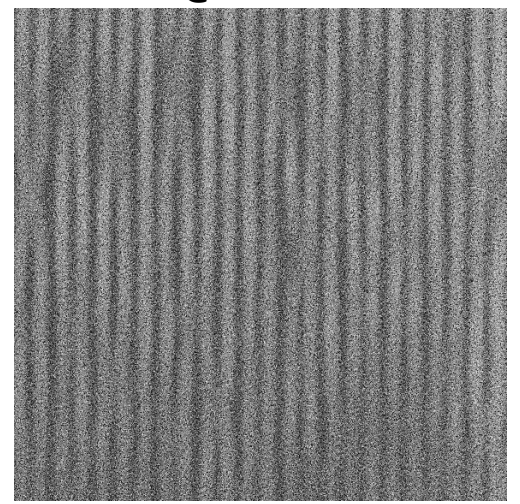

$\mathrm{HP}=13 \mathrm{~nm}$

R1@25 nm M2

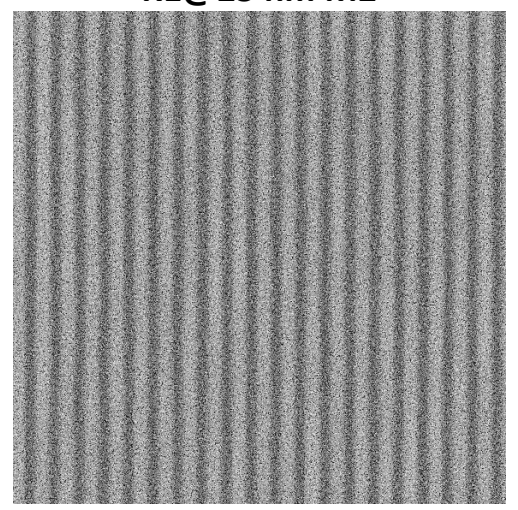

$\mathrm{HP}=11 \mathrm{~nm}$
R1@25 nm M2

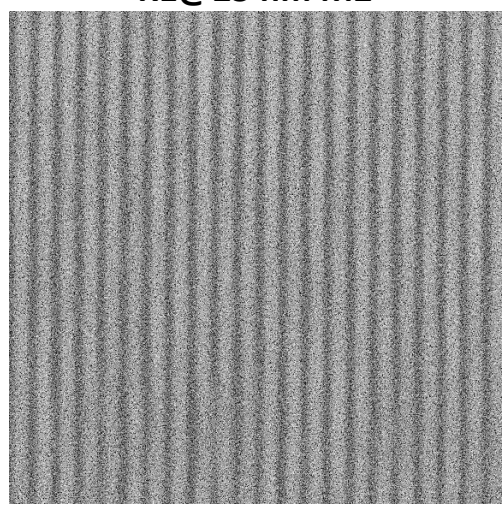

$\mathrm{HP}=14 \mathrm{~nm}$

R1@25 nm M2

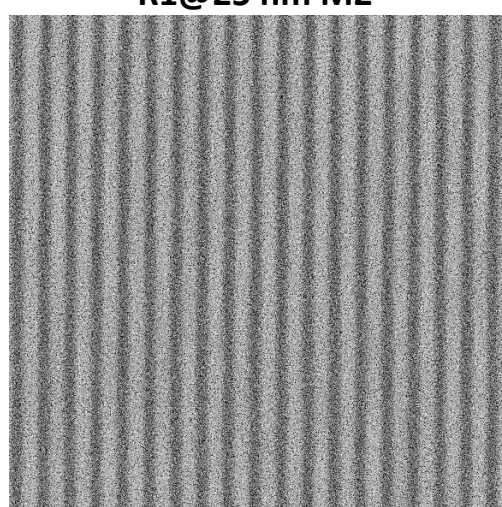

$\mathrm{HP}=12 \mathrm{~nm}$

Figure 10. SEM images for resist (R15UL1) for $11 \mathrm{~nm}$ to $14 \mathrm{~nm}$ HPs (for line-space 1:1 LS patterns). The pictures show SEM images obtained using M2 that includes HPs $<16 \mathrm{~nm}$ (and a resist R15 thickness $=25 \mathrm{~nm}$ ).
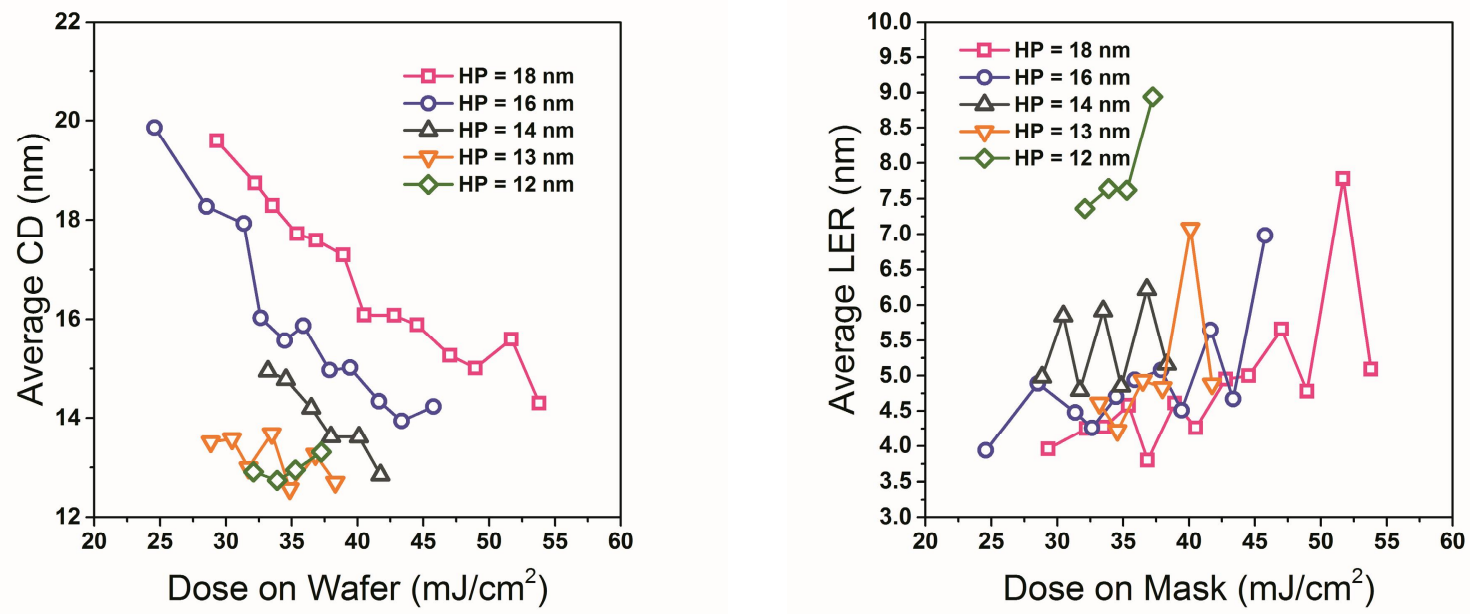

Figure 11. CD and LER plots for the HPs $\leq 18 \mathrm{~nm}$ possible $(H P=18,16,14,13$ and $12 \mathrm{~nm})$ when using R15UL1. The exposure was performed with $\mathrm{M} 2$. 


\begin{tabular}{|c|c|c|c|c|c|c|c|c|c|c|c|}
\hline \multicolumn{4}{|c|}{ HP: $14 \mathrm{~nm}$} & \multicolumn{4}{|c|}{ HP: 16 nm } & \multicolumn{4}{|c|}{ HP: $18 \mathrm{~nm}$} \\
\hline Name & $\begin{array}{l}\text { BE } \\
(\mathrm{mJ} / \mathrm{cm} 2)\end{array}$ & EL (\%) & LER $(\mathrm{nm})$ & Name & $\begin{array}{l}\mathrm{BE} \\
(\mathrm{mJ} / \mathrm{cm} 2)\end{array}$ & EL (\%) & LER $(\mathrm{nm})$ & Name & $\begin{array}{l}B E \\
(\mathrm{~mJ} / \mathrm{cm} 2)\end{array}$ & EL (\%) & LER $(\mathrm{nm})$ \\
\hline & & & & R1UL1 (30 nm) & \begin{tabular}{|r|}
30.96 \\
\end{tabular} & 27.45 & 2.95 & R1UL1 (30 nm) & \begin{tabular}{|r|}
31.68 \\
\end{tabular} & 29.83 & 2.87 \\
\hline 15UL1 (25 nm) & 37.43 & 8.84 & $4 . \varepsilon$ & R15UL1 $(25 \mathrm{~nm})$ & 36.07 & 24.95 & 4.95 & R15UL1 $(25 \mathrm{~nm})$ & 34.96 & 35.85 & 4.51 \\
\hline
\end{tabular}

Table 4. BE, EL, and LER for R15UL1 for $\mathrm{HP}=14 \mathrm{~nm}, 16 \mathrm{~nm}$, and $18 \mathrm{~nm}$. R1UL1 exposure experimental results are also included in this table for comparison. The exposures were performed in the same day with the same mask M2.

\section{CONCLUSIONS}

In this study we have focused on the performance qualification of different resists mainly for $18 \mathrm{~nm}$ and $16 \mathrm{~nm}$ half-pitch (16 nm logic half-pitch corresponds to the $3.5 \mathrm{~nm}$ logic industry node name estimated for production in 2021, ORTC technology trend targets, [12]) line/space resolution ( $\mathrm{L} / \mathrm{S}=1: 1)$. Among the most promising candidates tested here there are a few choices that allow for $16 \mathrm{~nm}$ HP resolution to be achieved with high exposure latitude (up to $~ 33 \%$ ) low LER (down to $3.3 \mathrm{~nm} \sim 20 \%$ of critical dimension CD) and low dose-to-size (best-energy, BE) $<41 \mathrm{~mJ} / \mathrm{cm}^{2}$ values. All being important metrics for the photolithography industry as it relates to high volume manufacturing. Furthermore, patterning was also demonstrated down to $11 \mathrm{~nm}$ HP with slight pattern collapse with one of the most promising chemically amplified resists tried here, R15UL1. A small process window was extraordinarily found at $\mathrm{HP}=14 \mathrm{~nm}$ for this resist with an EL $\sim 8 \%$. Though the LER was found to be unacceptably high for R15UL1 for a production environment $>25 \%$ of the nominal CD value for this ( $>35 \%$ HP $14 \mathrm{~nm},>25 \%$ for HP $=18 \mathrm{~nm}$ ), the small process window at such high resolution proves promising for future development and resist process improvement. This clearly demonstrates some of the problems faced when trying to improve the resolution of chemically amplified resists while simultaneously improving the LER and maintaining a wide exposure latitude. Though the $\mathrm{Z}$ factor as a simplified figure of merit can be a valuable first indication of resist performance, exposure attitude also needs to be considered into the equation if EUV photolithography is ever going to be commercially available.

\section{ACKNOWLEDGMENTS}

We would like to acknowledge Michaela Vockenhuber, Markus Kropf, Simon Tschupp, Daniel Fan and Nassir Mojarad for their technical expertise and assistance. We thank our various materials suppliers greatly. Part of this work was performed at the Swiss Light Source in the Paul Scherrer Institute.

\section{REFERENCES}

1. T. Wallow, C. Higgins, R. Brainard et al., in SPIE Advanced Lithography. (2008), vol. 6921, pp. 69211F.

2. $\quad$ E. S. Putna, T. R. Younkin, R. Caudillo et al., in SPIE Advanced Lithography. (2010), vol. 7636, pp. 76360P.

3. $\quad$ C. Anderson, in SPIE Advanced Lithography. (2013).

4. $\quad$ O. Ongayi, M. Christianson, M. Meyer et al., in SPIE Advanced Lithography. (2012), vol. 8322, pp. 83220T.

5. $\quad$ Y. Ekinci, M. Vockenhuber, M. Hojeij et al., in SPIE Advanced Lithography. (2013), vol. 8679, pp. 867910.

6. H. H. Solak, Y. Ekinci, P. Kaser et al., Photon-beam lithography reaches $12.5 \mathrm{~nm}$ half-pitch resolution. Journal of Vacuum Science \& Technology B: Microelectronics and Nanometer Structures 25, 91 (2007)10.1116/1.2401612).

7. B. Päivänranta, A. Langner, E. Kirk et al., Sub-10 nm patterning using EUV interference lithography. Nanotechnology 22, 375302 (2011).

8. N. Mojarad, D. Fan, J. Gobrecht et al., Broadband interference lithography at extreme ultraviolet and soft x-ray wavelengths. Optics Letters 39, 2286 (2014); published online Epub2014/04/15 (10.1364/OL.39.002286).

9. Y. Ekinci, M. Vockenhuber, B. Terhalle et al., in SPIE Advanced Lithography. (2012), vol. 8322, pp. 83220W.

10. D. J. Guerrero, in SPIE Advanced Lithography. (2014), vol. 9051, pp. 905114.

11. R. Sakamoto, B.-C. Ho, N. Fujitani et al., in SPIE - The International Society for Optical Engineering. (2011), vol. 7969, pp. 79692F.

12. Table ORTC1 Summary 2013 ORTC Technology Trend Targets. (2013), http://www.itrs.net/Links/2013ITRS/2013TableSummaries/2013ORTC_SummaryTable.pdf. 